\title{
Psychonephrology in Japan
}

\author{
Yoichi Ohtake
}

\begin{abstract}
Psychonephrology is the field of study encompassing nephrology, psychiatry, and psychosomatic medicine, which is based on the concept of consultation-liaison within the biopsychosocial model of mind-body unity. The Japanese Society for Psychonephrology was founded in Japan in 1990 to resolve psychological problems in dialysis patients and renal transplant patients, for whom survival time has increased. Patients with chronic kidney disease (CKD) face various psychological burdens during the time leading up to the initiation of renal replacement therapy (RRT) or through to the continuation of RRT. Patients with CKD may experience high levels of stress, poor physical conditions, medication side effects, as well as adjustment disorders and anxiety/depression. Additionally, close relationships between these patients and their family and medical staff can cause psychological stress in these other individuals. The three main domains in psychonephrology concern psychological care for patients, which includes drug therapy, psychotherapy, and environmental adjustments; interventions for psychosomatic disorders; and mental health care for staff involved in RRT. Interdisciplinary collaboration among psychiatrists, psychotherapists, nephrologists, transplant surgeons, and paramedics to resolve patients' problems has been promoted. Future developments in psychonephrology include adhering to patients' desires regarding discontinuation/withholding of dialysis and palliative care and shared decision-making during the time leading up to RRT. Further development of psychonephrology in Japan will help to maintain higher levels of quality of life in CKD patients and provide relief for their psychological issues.
\end{abstract}

Keywords: Psychonephrology, Psychosomatic medicine, Japan, Chronic kidney disease, Renal replacement therapy, Psychotherapy, Quality of life

\section{Background}

Psychonephrology is the field of study that focuses on nephrology and mental health fields such as psychiatry and psychosomatic medicine [1]. During the time leading up to the initiation of renal replacement therapy (RRT) or through to the continuation of RRT, patients with kidney disease face various psychological burdens. As a result, the area of psychonephrology has been expanding over time. Patients with kidney disease are now in need of a broad range of medical services beyond management of their psychological pain. Also required are support for decision-making during the time from conservative management of renal failure to the initiation of RRT, judgments on the discontinuation/withholding of RRT, and non-cancer palliative care for patients with chronic kidney disease (CKD). There are several reasons why the new field of psychonephrology focusing on CKD was established rather than other

Correspondence: yohtake.jp@gmail.com

1-1-1 Ebaraji-cho Nishi-ku Sakai, Osaka 593-8304, Japan serious physical diseases. First, CKD patients (especially with dialysis) usually experience high levels of stress and have characteristics not found in patients with other diseases. Second, CKD patients often suffer from poor physical conditions aside from their primary disease and medication side effects, which commonly manifest as psychological reactions. Third, close relationships between these patients and their family and medical staff can cause psychological stress in these other individuals.

\section{Brief overview of psychonephrology History of psychonephrology}

The origin of psychonephrology is considered to date back to 1978, when three liaison psychiatrists coined the term to highlight an aspect of American consultationliaison psychiatry and initiated a conference on this topic [1]. Since then, the conference has evolved into an international event held once every 2 years. Levy [2] later compiled the conference papers into a book entitled Psychonephrology. 


\section{Psychonephrology in Japan}

The Japanese Society for Psychonephrology (JSPN) [3] was founded in Japan in 1990 under the leadership of Dr. Kazuo Ohta and Dr. Shigekazu Haruki, mainly to resolve various psychological problems in dialysis patients and renal transplant patients. Around the same time, treatment outcomes of RRT in CKD patients dramatically improved in Japan, notably extending their survival. However, the intervention environments for CKD patients were far from ideal, and medical care for their psychological problems was particularly lacking. Since its inception, JSPN has held a convention every year, with the 26th installment having taken place in 2016. Aside from its national conventions, JSPN also organizes many regional study groups and workshops. In addition, the Japanese Society for Dialysis Therapy (JSDT) and other nephrology-related medical conferences have also seen an increase in symposiums or presentations on psychonephrology, with focus on providing support for patients' decision-making about RRT and the discontinuation/withholding of dialysis.

With the recent specialization and advancement in medical technologies, the need for team medical care has been re-recognized. As such, attempts have been made in the field of psychonephrology to promote interdisciplinary collaboration among psychiatrists, psychotherapists, nephrologists, transplant surgeons, and paramedics to resolve patients' problems, rather than each profession providing specialized care.

\section{Psychosomatic medicine in psychonephrology}

Along with psychiatric medicine, psychosomatic medicine has long been studied in Japan. Psychosomatic medicine is based on an academic framework that developed mainly in Japan and Germany and is characterized by a biopsychosocial model approach based on the notion of mind-body unity, rather than mind-body split. The history of psychosomatic medicine in Japan dates back to 1960, when Yujiro Ikemi and others established the Japanese Society of Psychosomatic Medicine [4]. Since then, departments of psychosomatic medicine have been established in some institutions across Japan (currently eight).

Similar to consultation-liaison psychiatry, the concept of consultation-liaison exists in psychosomatic medicine and is known as psychonephrology. Psychosomatic medicine is also involved in various other fields, such as psychosomatic respiratory disease, psychosomatic cardiovascular disease, and psycho-oncology. The field of primary care has a high affinity for the biopsychosocial model approach, which is also characterized by a particular focus on collaboration with paramedical staff in team medical care.

\section{Three domains of psychonephrology}

Three main domains in psychonephrology exist: (1) care for CKD patients, particularly psychological care associated with RRT; (2) interventions for psychosomatic disorders in CKD patients; and (3) mental health care for staff involved in RRT.

\section{Psychological care associated with CKD}

During the time leading up to the initiation of RRT, CKD patients experience a range of different kinds of psychological pain and use various defense mechanisms to cope with these pain types. Specifically, many experience anxiety, anger, resentment, tension, despair, and depression before finally coming to accept the necessity of undergoing RRT. However, some CKD patients continue to remain in denial even after the initiation of RRT, which often manifests as physical symptoms or nonadherence to treatment.

Similar to patients receiving a cancer diagnosis in general, it typically takes approximately 2 weeks for CKD patients to regain their psychological equilibrium after being notified of the need for RRT, which is a normal psychological reaction. However, some CKD patients may have a reaction known as an adjustment disorder, which delays their psychological recovery. Depending on the patients, anxiety/depression may last much longer than 2 weeks after notification, or in some cases, anxiety/ depression may worsen beyond the severity of an adjustment disorder and remain as a mood disorder (depressive state) (Fig. 1). Psychonephrology is also involved in the psychological care of these types of patients.

\section{Interventions for psychosomatic disorder in CKD patients}

The Japanese Society of Psychosomatic Medicine defines a psychosomatic disorder as "a physical condition with a structural or functional disorder in which psychological or social factors are closely involved in its onset or progress, with the exclusion of physical symptoms caused by other mental disorders such as neurosis and depression." The most common psychosomatic disorders include irritable bowel syndrome, migraine, and atopic dermatitis.

Patients with CKD may present with psychosomatically pathologic conditions or unidentified complaints. In the case of psychosomatically pathologic conditions, it is important to listen to the patient to elicit their explanatory model and to share hypotheses about the condition with the patient. Unidentified complaints can be regarded as physical manifestations of psychological suffering; therefore, it is necessary to explore and consider the patient's mental state underlying the condition. 


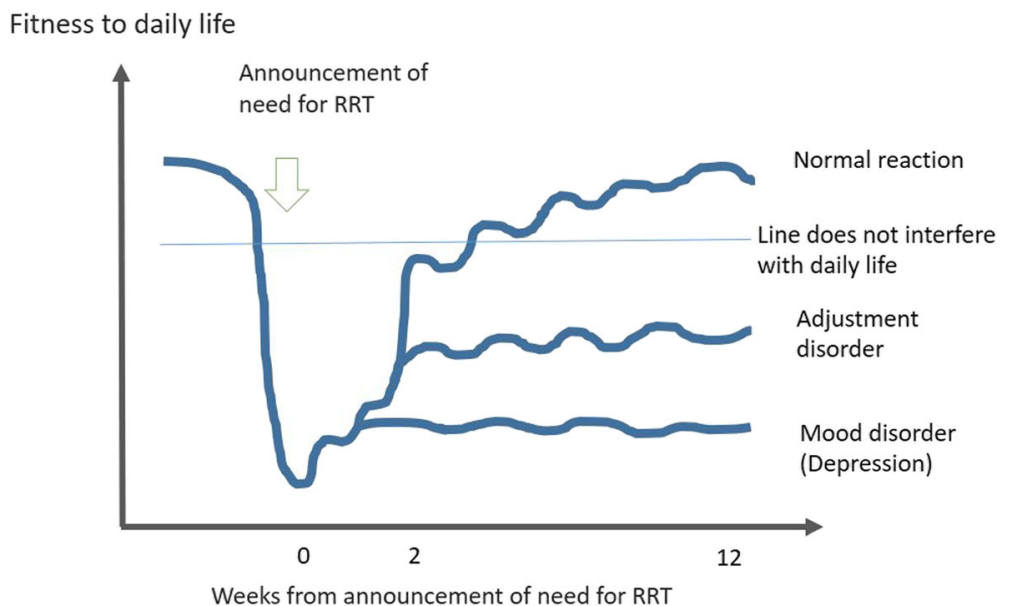

Fig. 1 Psychological reaction after announcement of need for RRT

\section{Mental health care for dialysis staff}

The majority of RRT performed in Japan is hemodialysis, which is most commonly administered in-center three times a week. Unlike with regular outpatient treatment, a much closer relationship can develop between hemodialysis patients and attending medical staff. It is ideal when this relationship produces positive effects on the patient's quality of life (QOL); however, unfortunately, this is not always the case. Because patients with kidney disease must cope with chronic conditions, they are sensitive to changes in their health and test results. A certain proportion is considered "difficult patients," who may persistently complain of their physical problems until they feel understood or think that their conditions are not being understood by their physicians. Therefore, a very close patient-doctor relationship must be maintained, which is also likely to cause psychological problems among dialysis staff.

In Japan, the "Amendment to the Industrial Safety and Health Act Industrial Safety and Health Act" was passed in June 2014, which requires employers of $\geq 50$ workers to offer Stress Checks in their workplaces at least once a year to assess levels of mental stress experienced by workers. Such mental health care for dialysis staff is also one of the domains of psychonephrology.

\section{The mental state of patients prior to receiving RRT} The mental process leading to the initiation of RRT

After years of undergoing outpatient treatment, many CKD patients come to somewhat accept their declining kidney function. However, RRT is sometimes required earlier than originally expected because of rapid deterioration or unexpected acute exacerbation of kidney function. In such cases, various psychological reactions may be seen in patients when notified that they need to undergo RRT; they usually experience disappointment/ hopelessness in the beginning, followed by denial, anxiety, anger, and depression before finally accepting RRT. This is very similar to the process of accepting death described in "On Death and Dying" by Elisabeth KüblerRoss [5]. However, unlike terminal cancer patients, CKD patients experience kidney death but continue to live. For this reason, the mental process leading to the initiation of RRT varies from case to case. It is also important to keep in mind that not all patients undergoing RRT have come to terms with the disease.

\section{Total pain}

Total pain is a concept of suffering mainly used in the area of palliative care, which was introduced by Cicely Saunders, a pioneer of modern hospice care [6]. Total pain is considered to be suffering that encompasses a person's physical, psychological, social, and spiritual pain. Figure 2 illustrates total pain experienced by CKD patients. It is essential that these problems be examined in a comprehensive and holistic manner. Particularly, psychological, social, and spiritual pain can easily be overlooked and thus require careful attention. While physical pain can be controlled to some degree by changing dialysis conditions, switching RRT modalities, or adjusting oral medications, the management of psychological pain is, as mentioned, a key part of psychonephrology.

\section{Defense mechanisms}

Reactions of the mind triggered by psychological crises during the time leading up to the initiation of RRT or during RRT are called defense mechanisms. Common defense mechanisms are presented in Table 1 . These defense mechanisms come in all manners and forms; they are essential to everyday life and include social adjustment behaviors such as sublimation and humor. The various defense mechanisms underlying the behavior of 


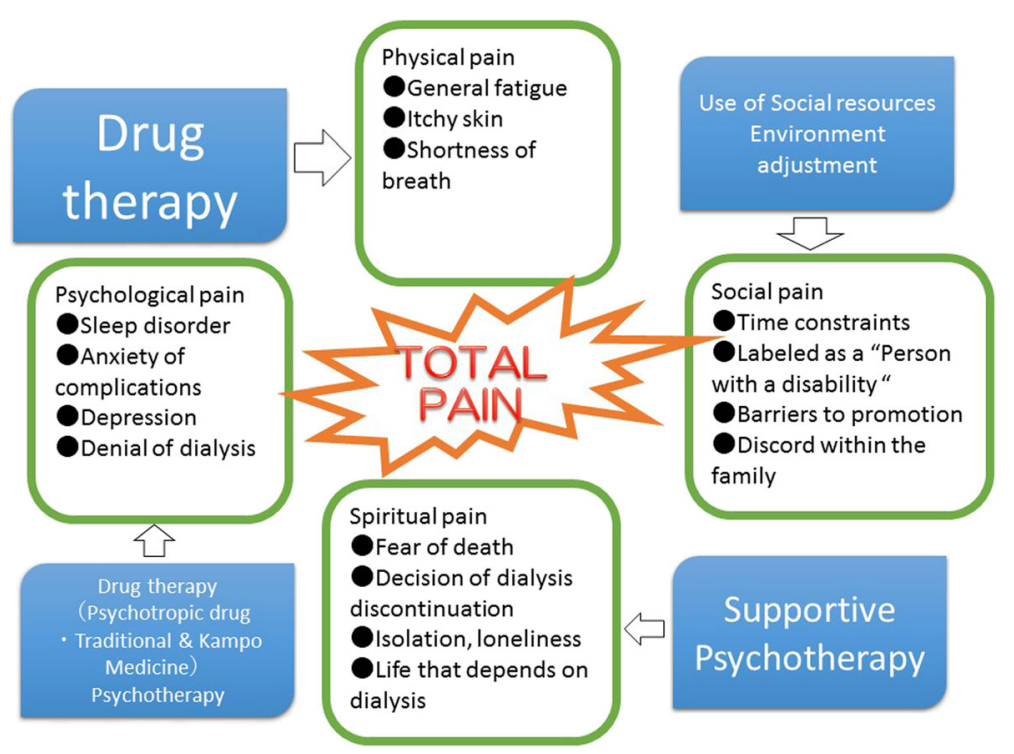

Fig. 2 Total pain of hemodialysis patient

patients with kidney disease should be considered and given close attention. In some patients, these defense mechanisms do not fully function, which may lead to the development of psychiatric diseases, such as depression and schizophrenia. Such cases should be referred to a psychiatrist immediately.

\section{Anxiety and depression}

According to studies published overseas, psychological tests conducted among dialysis patients have shown approximately $15-60 \%$ have "severe depressive symptoms" and $12-52 \%$ have "anxiety." With respect to disorders, approximately $10-20 \%$ of dialysis patients have been shown to meet DSM-IV criteria for major depressive disorder and $46 \%$ met criteria for some type of anxiety disorder. Among the variants in anxiety disorders, "panic disorder" is considered to be the most common in dialysis patients [7-9].

To treat such psychiatric conditions/diseases in patients with CKD, regular dialysis physicians are likely to use benzodiazepines. Benzodiazepines are easy to use in CKD patients because no renal function-based dose adjustment is necessary, which are primarily metabolized by the liver. In terms of their action mechanism, however, benzodiazepines are considered to be merely symptomatic treatment and have a high potential for dependence/tolerance. Conversely, patients with impaired kidney function and referred to a psychiatric or psychosomatic medicine department are often turned away or given no medication because of their kidney problems. Because many antidepressants and antipsychotics can be used in patients with impaired kidney function, it is optimal to work closely with a psychiatrist to support CKD patients with psychological problems.

\section{Effective psychotherapeutic approaches in psychonephrology}

Treatments for various psychological conditions can roughly be divided into (1) drug therapy, (2) psychotherapy, and (3) environmental adjustments. Particularly, rapid progress has been made in the field of psychotherapy, with a variety of approaches having been proposed in quick succession worldwide.

The psychotherapeutic approaches that are considered effective in psychonephrology are shown in Table 2. Although these approaches may employ various techniques and skills, all should focus on how patients can improve their self-control abilities using the resources
Table 1 Various defense mechanisms

\begin{tabular}{ll}
\hline Repression & Conversion \\
Projection & Somatization \\
Rationalization & Acting out \\
Sublimation & Denial \\
Displacement & Humor \\
\hline
\end{tabular}

Table 2 Psychotherapy used in psychonephrology

\begin{tabular}{ll}
\hline Supportive psychotherapy & Transactional analysis \\
Behavioral therapy & Autogenic training \\
Cognitive behavioral therapy & Family therapy \\
Solution-focused brief therapy & Interpersonal therapy \\
Motivational interviewing & Autonomy training \\
\hline
\end{tabular}


currently available to them. Furthermore, it is desirable to choose a psychotherapeutic approach that can help to manage decreased self-efficacy and self-control commonly seen in CKD patients.

\section{Future developments in psychonephrology}

As mentioned, psychonephrology was originally developed to resolve psychological problems in CKD patients. However, the area of psychonephrology is gradually expanding to assist with various problems occurring at clinical sites. Two future development paths for psychonephrology are described in the following sections.

\section{Discontinuation/withholding of dialysis and non-cancer palliative care}

In Japan, the primary reason for the introduction of dialysis treatment is diabetic nephropathy, and the age of patients at the start of dialysis is growing older each year, reaching 69 years old at present time. Under such circumstances, ethical issues such as whether to introduce dialysis to CKD patients with complications and when to stop dialysis in patients currently receiving it need to be dealt with urgently. At the 53rd annual meeting of the JSDT, Seiji Ohira gave a presentation entitled "Consideration for not Starting Dialysis (Withholding) and Discontinuing Dialysis (Withdrawal)." In 2014, the study subgroup on withholding and withdrawal of dialysis established as a subsidiary organization of the hemodialysis guidelines commission of the JSDT published "Proposal for the Shared Decision-Making Process Regarding Initiation and Continuation of Maintenance Hemodialysis." [10] This proposal described the importance of respecting patients' autonomous decisions and providing support for patients' decision-making process as a medical team. It is evident that patients' desires should be regarded as the highest priority. However, in reality, patients are often unable to make decisions on their own due to dementia or old age and require family members to make decisions for them. This can place psychological burdens on family members, often hindering smooth decision-making. In such situations, medical staff in psychonephrology units need to assess the psychological status of the people concerned and take on a catalytic role in communication among different professionals, patients/ family members, and medical staff.

Such advance care planning, which includes advance directives (AD), is being increasingly advocated in the field of palliative care (Fig. 3). In Japan, the Kidney Disease Therapy Society has created an AD form based on survival with dignity, rather than death with dignity [11].

Additionally, the Japan Association for Clinical Ethics recommends the Physical Orders for Life Sustaining Treatment (POLST) developed in the USA [12]. The POLST is a document that includes specific instructions

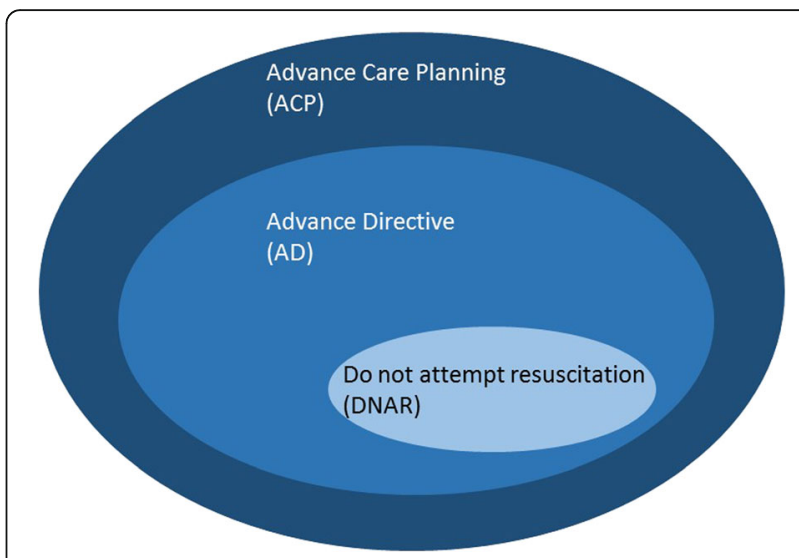

Fig. 3 Relationship of $A C P, A D$, and DNAR

regarding end-of-life care created based on the will of patients with severe progressive disease or chronic disease and contains more detailed instructions on medical interventions than Do Not Attempt Resuscitation instructions. The POLST form is created after consent has been obtained through in-depth discussion with patients or those who represent the patients. The POLST also contains an item about dialysis in Section C: other medical interventions.

At any rate, with the further aging of Japanese dialysis patients, the involvement of psychonephrology will be unavoidable to support decision making regarding discontinuation/withholding of dialysis and other matters, as well as the creation of $\mathrm{AD}$ forms.

In addition, in Japan, more than $90 \%$ of patients receiving palliative care are said to be cancer patients. However, palliative care is defined as an approach for addressing "life-threatening diseases," which include CKD. The Ministry of Health, Labour and Welfare (MHLW) formulated the Basic Plan to Promote Cancer Control based on the Cancer Control Act. As part of the plan, the PEACE Project (Palliative care Emphasis program on symptom management and Assessment for Continuous medical Education) was launched and has been implemented to help health care professionals engaged in cancer care to acquire basic knowledge and skills required in palliative care [13]. This 2-day program aims to enable participants to learn how to provide basic care to alleviate physical and psychological symptoms in typical cancer patients. The MHLW plans to disseminate palliative care into non-cancer fields; as its first step, the promotion of palliative care in cardiovascular diseases is already underway. Therefore, CKD will also be included in MHLW's plans, and psychonephrology approaches are expected to play an active role in palliative care for CKD patients, particularly in alleviating their psychological symptoms. 
Shared decision-making during the time leading up to RRT Previously, treatment methods prior to the initiation of RRT were often selected through paternalism, in which doctors make decisions on optimal treatment for their patients. However, this method began to face growing criticism with the spread of informed consent. In contrast to paternalism, an alternative approach was introduced where patients give informed consent after understanding and agreeing to the treatment explained. However, as with RRT, cases exist in which informed consent is impractical. For example, the patient may be unable to choose a treatment from multiple proposed options, the treatment chosen by the patient may not necessarily be the best option, or the patient may later change their mind based on information provided by medical staff. To resolve these concerns, the concept of shared decision-making was developed, through which "doctors provide patients with medical information, and the patients actively convey their values and preferences to the doctors so that the doctors and patients share the same information, thereby making it possible to choose the best treatment approach for the patients." [14] In shared decision-making, communication between patients and doctors is considered of utmost importance [10, 15].

For the implementation of shared decision-making, a three-step model was developed to facilitate the process [14]. The presence of psychiatrists/psychosomatic medicine physicians is also important because of their ability to create an atmosphere of trust and comfort as well as their third-person point of view.

\section{Conclusions}

Psychonephrology can be practiced by all health care professionals involved in RRT and is a growing area that is expected to see increased growth in future. Further development of psychonephrology in Japan will help to maintain higher levels of QOL in CKD patients and provide relief for their psychological issues.

\section{Abbreviations \\ AD: Advance directives; CKD: Chronic kidney disease; JSDT: Japanese Society for Dialysis Therapy; JSPN: Japanese Society for Psychonephrology; MHLW: Ministry of Health, Labour and Welfare; PEACE Project: Palliative care Emphasis program on symptom management and Assessment for Continuous medical Education Project; POLST: Physical Orders for Life Sustaining Treatment; RRT: Renal replacement therapy; QOL: Quality of life}

\section{Acknowledgements}

The authors would like to thank Dr. Atsuko Koyama who introduced me the world of psychonephrology.

\section{Funding}

None.

Availability of data and materials

Not applicable.

\section{Competing interests}

The authors declare that they have no competing interests.
Consent for publication

Not applicable.

Ethics approval and consent to participate

Not applicable.

\section{Publisher's Note}

Springer Nature remains neutral with regard to jurisdictional claims in published maps and institutional affiliations.

Received: 4 October 2016 Accepted: 9 March 2017

Published online: 09 June 2017

\section{References}

1. Levy NB. What is psychonephrology? J Nephrol. 2008;21:S51-3.

2. Levy NB, editor. Psychonephrology 1. Boston: Springer US; 1981.

3. The Japanese Society for Psychonephrology. http://www.jspn-ndt.com. Accessed 15 Sept 2016.

4. Japanese Society of Psychosomatic Medicine (JSPM). http://www.shinshinigaku.com/index.html. Accessed 15 Sept 2016.

5. Kübler-Ross E. On death and dying. New York: Routledge; 1969.

6. Richmond C. Dame Cicely Saunders. BMJ Br Med J. 2005;331:238.

7. Murtagh FE, Addington-Hall J, Higginson IJ. The prevalence of symptoms in end-stage renal disease: a systematic review. Adv Chronic Kidney Dis. 2007;14:82-99.

8. Cukor D, Coplan J, Brown C, Friedman S, Newville H, Safier M, et al. Anxiety disorders in adults treated by hemodialysis: a single-center study. Am J Kidney Dis. 2008;52:128-36.

9. Hedayati SS, Finkelstein FO. Epidemiology, diagnosis, and management of depression in patients with CKD. Am J Kidney Dis. 2009;54:741-52.

10. Watanabe Y, Hirakata H, Okada K, Yamamoto H, Tsuruya K, Sakai K, et al. Proposal for the shared decision-making process regarding initiation and continuation of maintenance hemodialysis. Ther Apher Dial. 2015;19:108-17.

11. Kidney Disease Therapy Society. http://www.geocities.jp/ chronickidneydisease/paper.html. Accessed 15 Sept 2016

12. Japan Association for Clinical Ethics. http://www.j-ethics.jp/workinggroup. htm. Accessed 15 Sept 2016

13. PEACE PROJECT. http://www.jspm-peace.jp. Accessed 15 Sept 2016.

14. Elwyn G, Frosch D, Thomson R, Joseph-Williams N, Lloyd A, Kinnersley P et al. Shared decision making: a model for clinical practice. J Gen Intern Med. 2012;27:1361-7.

15. Schell JO, Green JA, Tulsky JA, Arnold RM. Communication skills training for dialysis decision-making and end-of-life care in nephrology. Clin J Am Soc Nephrol. 2013:8:675-80.

Submit your next manuscript to BioMed Central and we will help you at every step:

- We accept pre-submission inquiries

- Our selector tool helps you to find the most relevant journal

- We provide round the clock customer support

- Convenient online submission

- Thorough peer review

- Inclusion in PubMed and all major indexing services

- Maximum visibility for your research 